\title{
EDITORIAL
}

\section{The psychological impacts of the climate crisis: a call to action}

\author{
Lise Van Susteren
}

Advisory Board for Center for Health and the Global

Environment; Harvard T. H. Chan School of Public Health: The Pychiatry Alliance, email Ivs350@me.com

\section{doi:10.1192/bji.2017.40}

(c) The Author 2018. This is an Open Access article, distributed under the terms of the Creative Commons Attribution-

NonCommercial-NoDerivatives NonCommercial-NoDerivatives
licence (http://creativecommons. licence (http://creativecommons.
org/licenses/by-nc-nd/4.0/), which permits non-commercial re-use, distribution, and reproduction in any medium, provided the original work is unaltered and is properly cited. The written permission of Cambridge University Press must be obtained for com mercial re-use or in order to create a derivative work.
A report released by the White House in April 2016 reviewed the impacts of climate change on human health in the USA (USGCRP, 2016). The report cited the injuries, deaths, disruption and displacement from increasingly frequent and intense heat waves, fires, droughts, floods, extreme weather events and rising sea level. It also reported on the increase in infectious diseases and - associated with pollution from higher temperatures - asthma, cardiovascular disease, pulmonary disorders, obesity and cancers. Of special interest, the report addressed the oftenoverlooked psychological impacts of climate change, devoting an entire chapter to carefully vetted, evidence-based data.

Mental health professionals will see the links between extreme weather and climate events causing huge loss of life, property, and community and psychological suffering. Individual and institutional avoidance of this exceedingly painful topic is rampant.

An overview of the mental health impacts in this report may be summed up as follows: humanity is already suffering - and will increasingly suffer - varying degrees and types of psychological harm as climate-related disasters alter how and where we live, and, in some cases, if we live. Many people will not experience the effects directly but will suffer vicariously in empathic identification with the victims. The cumulative toll of repeated events will be especially challenging. Many will suffer at the thought of what they fear is coming and indeed what they are being told is coming. A full range of psychological disorders is emerging, and increased incidence of depression, anxiety, and trauma-related conditions may be expected. Some of these conditions will become chronic. The study also refers to post-traumatic growth - suggesting positive psychological outcomes from trauma - but to those on the front lines, it may seem like cold comfort. The misuse of alcohol and drugs in an attempt to cope with stress will be more common. Domestic violence and child abuse will rise. Those who are elderly, sick, disabled, children and those individuals from low-income communities are especially vulnerable, as are those living in the centre of disaster-prone areas: along coastlines and rivers; 'tornado alleys'; inner cities, where temperatures are particularly high due to the 'heat-island' effect; and lands stricken by drought. Emergency workers rank high on the list of those who are vulnerable. People with mental illness are at special risk they have fewer resources and less general resilience. Getting these people to safe ground can be unusually challenging, and disruption of treatment can quickly lead to decompensation. At higher temperatures, psychotropic drugs carry more life-threatening side effects. The report notes that cultivating resilience and general resourcefulness will mitigate some of the impacts.

The White House report was expressly envisioned as a first step. Below are amplifications and additions that build on the report, with special emphasis on the geopolitical ramifications and impacts that carry the heaviest burdens, along with a special call for help from mental health professionals - because we are trained and naturally inclined to urge people to change for the good and safety of all.

\section{Aggression}

The report cites the link between extreme climate and weather events to an increase in aggression. Not included in the report were the precise numbers:

For each standard deviation of increased temperature and change in rainfall, society can expect a $4 \%$ increase in conflict between individuals and a $14 \%$ increase in conflict between groups (Hsiang et al, 2013).

Behind the numbers lie more assaults, murder, suicides, domestic violence - including child abuse, as well as increasing global unrest because these findings are valid for all ethnicities and across every region.

\section{Cognition}

Exposing workers to increasing levels of carbon dioxide has a major impact on cognitive functioning. Testing at concentrations to which Americans are frequently exposed indoors shows the most serious decline in our ability to think strategically, to use information and to respond to a crisis (Datz, 2015).

\section{Air quality}

Smog from pollution forms more quickly at higher temperatures. It is linked to multiple mental and physical health problems:

The American Psychological Association reported children exposed to small particles of chemicals in the air are more likely to have symptoms of anxiety or depression (Weir, 2012).

Emergency room visits for anxiety and suicide threats are significantly higher on days with poor air quality (Szyszkowicz et al, 2010). 
Polluted air causes neuro-inflammation that is linked to neurodegenerative disorders such as Alzheimer's disease, Parkinson's disease and amyotrophic lateral sclerosis (Frank-Cannon et al, 2009; Calderón-Garcidueñas et al, 2015). It is also linked to psychiatric disorders (Lundberg, 1996; Oudin et al, 2016).

\section{'Not everything that counts can be counted'}

The authors of the report confined themselves to the psychological impacts from climate change that were measurable. As important as these are, much of the psychological harm comes from complex stressors and is hard to measure. But it is these sweeping psychological effects, inchoate though they may be, from the massive-scale disruptions that are the guts of the psychological toll and show why immediate action is needed and why alarm is so legitimate.

Predictions of upstream triggers show that unless immediate major changes are made to reduce greenhouse gas emissions, irreversible catastrophes will be set in motion:

The Middle East, experts have predicted, may be uninhabitable by the end of the century (Funkhouser, 2016).

As many as $50 \%$ of all living species may be on the road to extinction by mid-century (Thomas et al, 2004).

\section{Refugee crisis}

Of all the traumatic consequences of climate change, one of the most dramatic is the prediction that hundreds of millions of refugees will soon be searching for safety (Vaughan, 2016). Antonio Guterres, the United Nations High Commissioner for Refugees, has declared that we "no longer have the resources ... to pick up the pieces...' (Welsh, 2015).

\section{Professional opportunities}

The canon of ethics of many organizations, including the American Psychiatric Association, declares that we have a responsibility to recognise the need to protect public health (American Medical Association, 1995-2016).

Mental health professionals are well positioned to challenge denial, influence public policy and care for the victims of climate disasters because of our clinical training and expertise. We can address psychological mechanisms of defence and harmful behaviour and use our skills in treating the impacts of illness and injury.

This urgent call to action is further conveyed by the choices we make to live sustainably in our professional and personal lives - because we also lead by example.

\section{References}

American Medical Association (1995-2016). Code of Medical Ethics.

Calderón-Garcidueñas L., Calderón-Garcidueñas A., Torres-Jardón R., et al (2015) Air pollution and your brain: what do you need to know right now. Primary Health Care Research and Development, 16, 329-345.

Datz T. (2015) Green Office Environments Linked with Higher Cognitive Function Scores. Harvard T.H. Chan School of Public Health.

Frank-Cannon T. C., Alto L. T., McAlpine F. E., et al (2009) Does neuroinflammation fan the flame in neurodegenerative diseases? Molecular Neurodegeneration, 4, 7

Funkhouser D. (2016) Climate May Make Some Regions 'Uninhabitable' by End of Century. State of the Planet [online]. Earth Institute, Columbia University. Available at: http://blogs.ei.columbia. edu/2016/03/02/climate-may-make-some-regions-uninhabitable-byend-of-century/ (accessed 8 January 2018).

Hsiang S., Burke M. \& Miguel E. (2013) Quantifying the influence of climate change and human health. Science AAAS, 341.

Lundberg A. (1996) Psychiatric aspects of air pollution. Otolaryngology and Head and Neck Surgery, 114, 227-231.

Oudin A., Bråbäck L., Âström D. O., et al (2016) Association between neighbourhood air pollution concentrations and dispensed medication for psychiatric disorders in a large longitudinal cohort of Swedish children and adolescents. BMJ Open, 6, e010004.

Szyszkowicz M., Willey J. B., Grafstein E., et al (2010) Air pollution and emergency department visits for suicide attempts in Vancouver, Canada. Environmental Health Insights, 4, 79-86.

Thomas C. D., Cameron A., Green R. E., et al (2004) Extinction risk from climate change. Nature 427, 145-148.

United States Global Change Research Program (USGCRP) (2016) The Impacts of Climate Change on Human Health in the United States: A Scientific Assessment. United States Global Change Research Program.

Vaughan A. (2016) French minister warns of mass climate change migration if world doesn't act. The Guardian, 26 May. Available at: https://www.theguardian.com/environment/2016/may/26/frenchminister-warns-of-mass-climate-change-migration-if-world-doesnt-act [accessed 8 January 2018].

Weir K. (2012) Smog in our brains: researchers are identifying startling connections between air pollution and decreased cognition and well-being. American Psychological Association, 43, 32.

Welsh T. (2015) UN Report: In New Record, 60 Million Displaced Worldwide: A Wealth of Global Conflicts Have Contributed to the Staggering Refugee Crisis across the World. U.S. News. U.S. News \& World Report L.P. 